\title{
COMPARATIVE ESTIMATION OF HEAT SHOCK PROTEIN 70 (HSP 70) EXPRESSION IN HEALTH, GINGIVITIS AND PERIODONTITIS.
}

\section{Dr. D.Dhivya Darshani ${ }^{1}$, Dr. Nithya Anand ${ }^{2}$, Dr. Vidyarani Shyamsundar ${ }^{3}$, Dr. Bagavad Gita ${ }^{4}$}

${ }^{1}$ Senior lecturer, Department of Periodontology, Bharath Institute of Higher Education and Research, Sree Balaji Dental College and Hospitals.

${ }^{2}$ Professor, Department of Periodontology, Bharath Institute of Higher Education and Research, Sree Balaji Dental College and Hospitals.

${ }^{3}$ Professor, Department of Oral Pathology and Microbiology, Center for Oral Cancer Prevention Awareness and Research, Bharath Institute of Higher Education and Research, Sree Balaji Dental College and Hospitals.

${ }^{4}$ Professor \& Head of the department, Department of Periodontology, Bharath Institute of Higher Education and Research, Sree Balaji Dental College and Hospitals.

\section{Article Info: Received 10 January 2020; Accepted 27 February 2020}

DOI: https://doi.org/10.32553/jbpr.v9i1.720

Corresponding author: Dr. D. Dhivya Darshani

Conflict of interest statement: No conflict of interest

\section{ABSTRACT:}

Background: Although periodontal bacteria are the causative agents of periodontitis, subsequent progression and disease severity are thought to be determined by a host's immune responses. HSPs may be expressed during periodontal diseases.

Objective: To compare the HSP 70 expression within layers of epithelium and connective tissue and correlate the expression of HSP 70 with the severity of periodontal disease.

Materials \& Methods: The study population comprised of 25 patients with periodontitis, and 23 patients with gingivitis and 21 controls with healthy gingival; tissue samples collected from the Department of Periodontology /Oral and Maxillofacial Surgery respectively. An immunohistochemical analysis was done for HSP 70 expression.

Results: One way ANOVA results indicate a statistically significant expression in basal layer for mild inflammation (mean=2.36) and intensity in stratum spinosum for mild (mean=2.27) and minimum (mean=2.39) inflammation. An overall greater HSP 70 expression is noticed in periodontitis group (total IRIDI $=25.41$ ) however not statistically significant

Conclusion: We elucidated that there was significant HSP 70 expression in stratum basale and spinosum for mild inflammation that did not increase with severity of inflammation. The overall expression of HSP70 is insignificantly elevated in periodontitis compared to health \& gingivitis.

Statistical analysis used: One way Analysis of Variance (ANOVA), Mann Whitney $U$ test and Kruskal Wallis Test.

Keywords: Heat shock protein 70 (HSP 70), Immunohistochemistry (IHC), Porphyromonas gingivalis.

\section{Introduction}

Periodontitis is defined as "an inflammatory disease of the supporting tissues of the teeth caused by specific microorganisms or groups of specific microorganisms, resulting in progressive destruction of the periodontal ligament and alveolar bone with pocket formation, recession, or both ${ }^{1}$. When exposed to a wide range of environmental stresses (temperature, $\mathrm{pH}$, redox potential, etc.), prokaryotic and eukaryotic cells respond by inducing or accelerating the synthesis of specific proteins known as stress proteins, including heat-shock proteins (HSPs). HSPs are expressed constitutively under normal conditions but are quickly up-regulated under stressful conditions.
HSPs act as molecular chaperones in the assembly and folding of proteins, and as proteases when damaged or toxic proteins have to be degraded ${ }^{2,3}$. Heat shock proteins ( $\mathrm{Hsp}$ ) are highly conserved proteins found in all prokaryotes and eukaryotes. In response to a wide variety of stressful stimuli, there is a marked increase in total Hsp synthesis ${ }^{3}$, known as the cellular stress response. The stress response is designed to enhance the ability of the cell to cope with increasing concentrations of unfolded or denatured proteins. Of all heat shock proteins, the Hsp70 family constitutes the most conserved and best-studied class. 
Heat shock proteins play an essential role in the etiology of numerous diseases, with a rapidly increasing role in clinical practice ${ }^{4,5,6}$. HSPs may be expressed during periodontal diseases ${ }^{7}$. Although periodontal bacteria like Porphyromonas gingivalis, and Aggregatibacter actinomycetemcomitans are the causative agents in Periodontitis, the progression of the disease and the amount of severity is known to be controlled by host immune responses ${ }^{8}$. HSP70 bound with high affinity to the plasma membrane, elicited a rapid intracellular calcium flux, activated nuclear factor (NF)-kappaB and upregulated the expression of pro-inflammatory cytokines tumor necrosis factor (TNF)-alpha, interleukin (IL)-1beta and IL- 6 in human monocytes ${ }^{9}$. Therefore, the present study aimed to determine the expression of HSP70 molecule and their possible role in the etiopathogenesis of periodontal disease.

In periodontal disease as per the current evidence the host immuno inflammatory response to pathogenic bacteria play a key role in disease progression. Salivary HSP 70 induces such autoimmune mechanisms that contribute to the initiation of gingivitis ${ }^{10}$ and also since mainly secreted in a lipid bound form and so protein bound lipid molecules are known to form nucleus of calcium-phosphate deposition leading to calculus formation so that takes part in the acquired pellicle formation on tooth surfaces and gingival inflammation under certain conditions ${ }^{11,12}$. Molecular mimicry between GroEL of the periodontopathic Porphyromonas gingivalis and autologous human HSP 60 may play a role in immune mechanisms of periodontal disease ${ }^{13}$.

\section{Materials and methods}

\section{Inclusion criteria}

Sixty nine individuals aged $20-55$ years were included in the study with a minimum of $\geq 20$ teeth in the dentition and categorized into three groups.

Group A- Healthy gingiva; gingival index score 0 (LOE H \& SILNESS et al 1963).

Group B - The criteria for gingivitis will be no attachment loss and a gingival index of 1 or 3 (LOE H, SILNESS et al 1963).

Group C - The criteria for periodontitis is $>3 \mathrm{~mm}$ of clinical attachment loss (CAL) and probing depth (PD) > $5 \mathrm{~mm}$ (Flemming et al 1999).

The clinical parameters recorded are gingival index, pocket probing depth \& clinical attachment level.

\section{Exclusion criteria}

Individuals excluded include who had undergone periodontal /antibiotic therapy within past six months, previous history of cardiovascular disease, inflammatory conditions, hepatic or thyroid disease, use of drugs, pregnant and lactating mothers.

\section{Tissue collection}

Biopsies were obtained (one biopsy per patient) by making two parallel vertical incisions (approximately 4 $\mathrm{mm}$ apart) connected by a horizontal incision made at approximately $1 \mathrm{~mm}$ below the base of the gingival sulcus with no-15 blade and BP handle. For the healthy and gingivitis group, gingival biopsies were obtained at the time of extraction.

For the periodontitis category, biopsies were obtained at the time of flap surgery, done to eliminate periodontal pockets. All the tissue specimens were fixed in $10 \%$ neutral buffered formalin. The tissues were embedded in Paraffin wax for the histopathological examination and IHC.

\section{Antibodies}

The primary antibody is Anti-Heat Shock Protein (HSP70), BioGenex Laboratories, San Ramon, CA, (AM289$5 \mathrm{M})$. The secondary antibody is Mouse/Rabbit polydetector HRP/DAB detection kit BioSB (BSB-0201). For all the tissues $\mathrm{H}$ and $\mathrm{E}$ stained sections were obtained. The $\mathrm{H}$ and $\mathrm{E}$ stained sections were reviewed for the adequacy of the epithelium and CT.

\section{Histopathological grading of IHC slides}

The IHC slides were viewed under 10X and 20X magnification objective by a senior oral pathologist and PI. All the clinical findings were blinded. The grading was done separately for the basal layer, parabasal layer \& stratum spinosum. The grading was done using ProgResCapture Pro 2.8.8 JENOPTIK OPTICAL SYSTEMS software. The slides were focused on 20x and live image was obtained in the computer screen. 100 cells were marked on the computer for each layer for each field. Out of 100 cells marked, positive cells were counted to obtain the percentage positivity. This procedure was repeated for 10 (20x) fields.

The percentage positivity was graded as Grade 0 - $\leq 10 \%$ positive or immunoreactive cells, Grade $1-11 \%$ to $25 \%$ positive cells, Grade $2-26 \%$ to $50 \%$ positive cells, Grade $3-51 \%$ to $75 \%$ positive cells; Grade $4-\geq 76 \%$ positive cells 14 . The intensity of staining was recorded as score 1 for light yellow or mild staining, score 2 for yellow or moderate staining, and score 3 for brown or intense staining $^{15}$ (figure 1). In the connective tissue, the percentage positivity was counted in 10 (40x) fields and mean value was obtained. The cells counted were the inflammatory cells and fibroblasts. Immunohistochemical evaluation was performed according to Chaiyarit et al $1999^{14}$. The kappa statistic valve for 
interobserver variability was almost a perfect agreement (0.85).

\section{IRIDI calculation}

Immunoreactivity intensity distribution index (IRIDI) scores were obtained by multiplying the grade of positive cells and intensity of staining. The final scores ranged from 0 to 12. A median score was then calculated. The tissue with scores equal to or more than median were defined as the high expression group and those with scores less than median were defined as the low expression group ${ }^{16}$. IRIDI scores were calculated for the basal, parabasal layer, stratum spinosum and for the connective tissue of all the patient samples as well as control samples.

\section{Results}

A statistical evaluation was performed. Comparison of mean values of two groups is done using independent samples t-tests. Comparison of mean values of more than two groups is done using oneway Analysis of Variance (ANOVA). To compare the equality of proportions among the two groups, Mann Whitney $U$ test has been applied and to compare the equality of proportions among more than two groups, Kruskal Wallis Test has been applied.

There is a greater intensity and staining in all the epithelium layers compared to connective tissue (figure $1 a, 1 b, 1 c)$ although not statistically significant this may be because of smaller sample size. More hyperplastic epithelium is seen with age which is significant (.024) (Table 1).

Figure 1a, 1b, 1c there is greater intensity \& staining in all the epithelium layers compared to connective tissue.

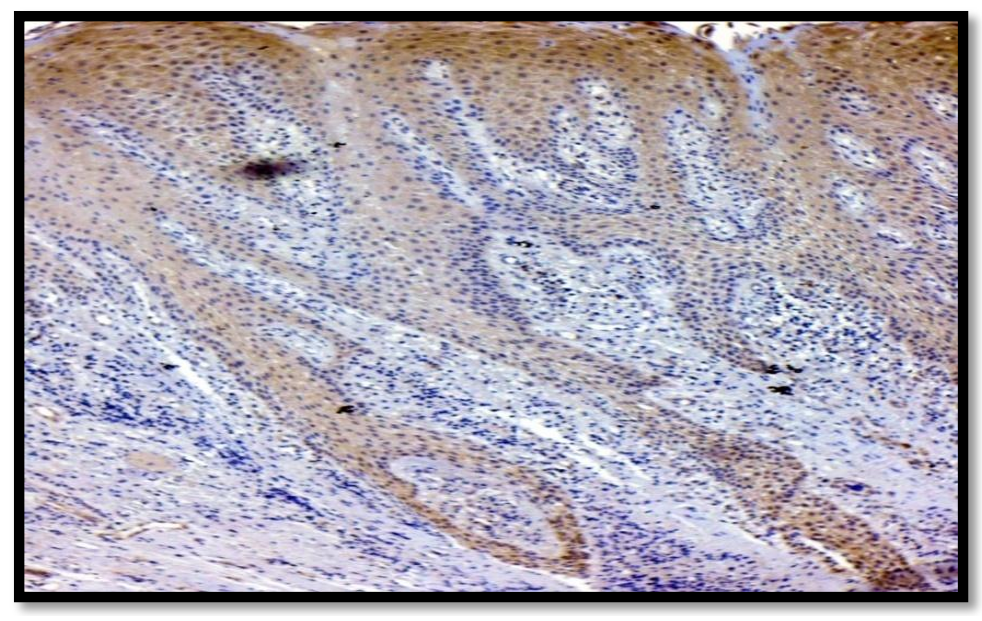

Fig 1a: Mild positivity (Grade I intensity) seen throughout the epithelium. IHC, 10X

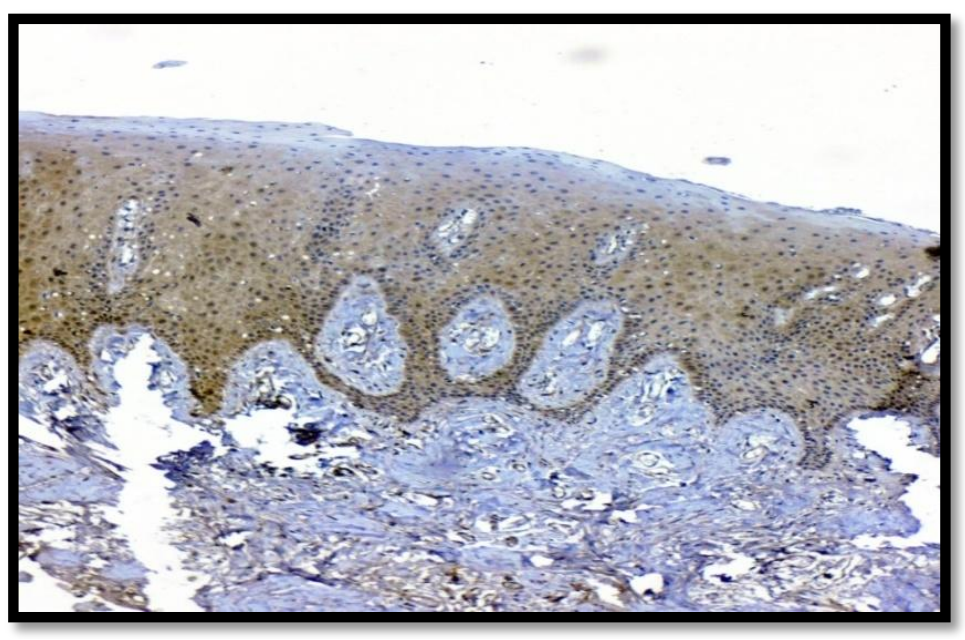

Fig 1b: Moderate positivity (Grade II intensity) seen throughout the epithelium. IHC, 10X. 


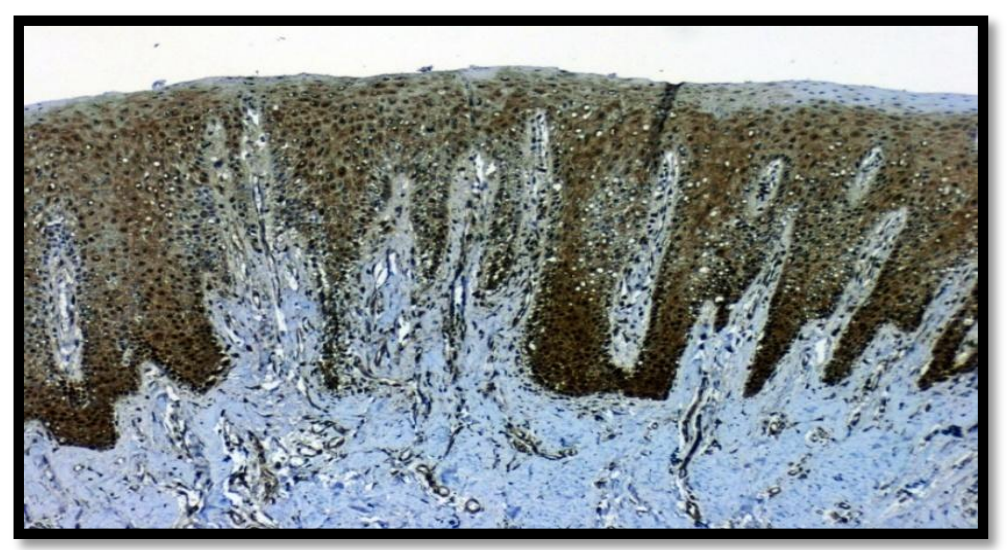

Fig 1c: Intense positivity (Grade III intensity) seen throughout the epithelium. IHC, 10X.

\section{TABLE 1: Group Statistics and Independent Samples t-test}

\begin{tabular}{|c|c|c|c|c|c|c|c|}
\hline & Epithelium & $\mathrm{N}$ & Mean & Std. Deviation & $\begin{array}{l}\text { Std. Error } \\
\text { Mean }\end{array}$ & t-Value & Sig. \\
\hline \multirow[t]{2}{*}{ Age } & Hyperplastic & 35 & 43.91 & 13.742 & 2.323 & 2.314 & 0.024 \\
\hline & Normal & 32 & 35.63 & 15.581 & 2.754 & & \\
\hline \multirow[t]{2}{*}{ Epithelium basal } & Hyperplastic & 38 & 3.45 & .724 & .117 & -0.933 & 0.354 \\
\hline & Normal & 33 & 3.61 & .704 & .123 & & \\
\hline \multirow[t]{2}{*}{ Ebasal Intensity } & Hyperplastic & 38 & 2.00 & .930 & .151 & -0.902 & 0.370 \\
\hline & Normal & 33 & 2.18 & .769 & .134 & & \\
\hline \multirow[t]{2}{*}{ Ebasal IRIDI score } & Hyperplastic & 38 & 7.24 & 4.096 & .665 & -0.921 & 0.360 \\
\hline & Normal & 33 & 8.06 & 3.436 & .598 & & \\
\hline \multirow[t]{2}{*}{ Epithe Parabasal } & Hyperplastic & 38 & 3.63 & .675 & .109 & 0.161 & 0.873 \\
\hline & Normal & 33 & 3.61 & .659 & .115 & & \\
\hline \multirow[t]{2}{*}{ E Para Intensity } & Hyperplastic & 38 & 1.97 & .885 & .144 & -0.285 & 0.776 \\
\hline & Normal & 33 & 2.03 & .770 & .134 & & \\
\hline \multirow{2}{*}{$\begin{array}{l}\text { EPara } \\
\text { IRIDI score }\end{array}$} & Hyperplastic & 38 & 7.32 & 3.721 & .604 & -0.371 & 0.711 \\
\hline & Normal & 33 & 7.64 & 3.516 & .612 & & \\
\hline \multirow[t]{2}{*}{ Epithe st spinosum } & Hyperplastic & 38 & 3.50 & 1.180 & .191 & -1.295 & 0.200 \\
\hline & Normal & 33 & 3.79 & .650 & .113 & & \\
\hline \multirow[t]{2}{*}{ ESS Intensity } & Hyperplastic & 38 & 2.03 & 1.052 & .171 & -1.140 & 0.258 \\
\hline & Normal & 33 & 2.27 & .761 & .133 & & \\
\hline \multirow[t]{2}{*}{ ESS IRIDI score } & Hyperplastic & 38 & 7.74 & 4.323 & .701 & -1.206 & 0.232 \\
\hline & Normal & 33 & 8.85 & 3.438 & .598 & & \\
\hline \multirow[t]{2}{*}{ Total IRIDI Score } & Hyperplastic & 38 & 22.29 & 11.128 & 1.805 & -0.947 & 0.347 \\
\hline & Normal & 33 & 24.55 & 8.927 & 1.554 & & \\
\hline \multirow[t]{2}{*}{ CT stain } & Hyperplastic & 38 & 1.45 & 1.655 & .269 & -0.652 & 0.516 \\
\hline & Normal & 33 & 1.70 & 1.551 & .270 & & \\
\hline \multirow[t]{2}{*}{ CT intensity } & Hyperplastic & 38 & .92 & 1.075 & .174 & -1.134 & 0.261 \\
\hline & Normal & 33 & 1.21 & 1.083 & .188 & & \\
\hline \multirow[t]{2}{*}{ CT IRIDI score } & Hyperplastic & 38 & 2.84 & 4.064 & .659 & -0.558 & 0.579 \\
\hline & Normal & 33 & 3.39 & 4.264 & .742 & & \\
\hline
\end{tabular}

Oneway ANOVA results indicate a statistically significant expression in basal layer for mild inflammation (mean=2.36) and intensity in stratum spinosum for mild (mean=2.27) and minimum (mean=2.39) inflammation (Table 2).

Table 2: Comparison of mean values in different groups of inflammation (one way anova)

\begin{tabular}{|c|c|c|c|c|c|c|c|c|c|c|}
\hline & \multicolumn{8}{|c|}{ Inflammation } & \multirow{2}{*}{\multicolumn{2}{|c|}{ One way ANOVA }} \\
\hline & \multicolumn{2}{|c|}{ Minimum $(n=28)$} & \multicolumn{2}{|c|}{$\operatorname{Mild}(n=22)$} & \multicolumn{2}{|c|}{ Moderate $(n=13)$} & \multicolumn{2}{|c|}{ Dense $(n=5)$} & & \\
\hline & Mean & $\mathrm{SE}$ & Mean & $\mathrm{SE}$ & Mean & SE & Mean & SE & F Value & Sig. \\
\hline Age & 36.11 & 2.67 & 38.67 & 3.47 & 47.67 & 4.62 & 45.43 & 4.51 & 2.075 & 0.113 \\
\hline Epithelium basal & 3.46 & .14 & 3.68 & .17 & 3.38 & .18 & 3.50 & .19 & 0.580 & 0.630 \\
\hline Ebasal Intensity & 2.18 & .15 & 2.36 & .18 & 1.77 & .23 & 1.50 & .33 & 2.938 & 0.039 \\
\hline Ebasal IRIDI score & 7.89 & .70 & 8.95 & .79 & 6.08 & .92 & 5.50 & 1.43 & 2.677 & 0.054 \\
\hline Epithe parabasal & 3.46 & .16 & 3.73 & .12 & 3.69 & .13 & 3.75 & .16 & 0.857 & 0.468 \\
\hline E Para Intensity & 2.11 & .15 & 2.09 & .17 & 1.85 & .25 & 1.63 & .32 & 0.939 & 0.427 \\
\hline E Para & 7.64 & .70 & 8.00 & .72 & 6.92 & 1.05 & 6.25 & 1.37 & 0.574 & 0.634 \\
\hline \multicolumn{11}{|l|}{ IRIDI score } \\
\hline Epithe st spinosum & 3.82 & .07 & 3.73 & .16 & 3.46 & .37 & 3.00 & .65 & 1.729 & 0.169 \\
\hline ESS Intensity & 2.39 & .13 & 2.27 & .19 & 1.92 & .29 & 1.25 & .41 & 3.960 & 0.012 \\
\hline ESS IRIDI score & 9.29 & .58 & 8.73 & .82 & 7.23 & 1.23 & 5.00 & 1.65 & 3.100 & 0.032 \\
\hline
\end{tabular}




\begin{tabular}{|c|c|c|c|c|c|c|c|c|c|c|}
\hline Total IRIDI Score & 24.82 & 1.79 & 25.68 & 2.00 & 20.23 & 2.90 & 16.75 & 4.24 & 2.228 & 0.093 \\
\hline CT stain & 1.36 & .25 & 1.41 & .38 & 1.77 & .47 & 2.38 & .63 & 0.979 & 0.408 \\
\hline CT intensity & 1.07 & .18 & .91 & .25 & 1.23 & .34 & 1.13 & .35 & 0.253 & 0.859 \\
\hline CT IRIDI score & 2.50 & .66 & 3.09 & 1.00 & 4.00 & 1.32 & 3.75 & 1.40 & 0.456 & 0.714 \\
\hline
\end{tabular}

The overall HSP 70 expression is more in periodontitis group (mean= 25.41) compared to gingivitis (mean= 22.96) or health (mean $=21.64)$ but not statistically significant $(p>0.01)$ (Table 3$)$.

Table 3: comparison of mean values in different groups of periodontal diseases (one wayanova)

\begin{tabular}{|c|c|c|c|c|c|c|c|c|}
\hline & \multicolumn{6}{|c|}{ Diagnosis } & \multirow{2}{*}{\multicolumn{2}{|c|}{ One way ANOVA }} \\
\hline & \multicolumn{2}{|c|}{ Gingivitis $(n=23)$} & \multicolumn{2}{|c|}{ Periodontitis $(n=25)$} & \multicolumn{2}{|c|}{ Healthy $(n=21)$} & & \\
\hline & Mean & SE & Mean & $\mathrm{SE}$ & Mean & SE & F Value & Sig. \\
\hline Age & 36.87 & 1.71 & 56.96 & 1.86 & 24.52 & 1.21 & 98.724 & 0.000 \\
\hline Epithelium basal & 3.50 & .15 & 3.74 & .09 & 3.27 & .19 & 2.786 & 0.069 \\
\hline Ebasal Intensity & 2.08 & .19 & 2.19 & .17 & 2.00 & .16 & 0.284 & 0.754 \\
\hline Ebasal IRIDI score & 7.67 & .85 & 8.30 & .71 & 6.86 & .74 & 0.864 & 0.426 \\
\hline Epithe para basal & 3.54 & .16 & 3.81 & .08 & 3.45 & .16 & 2.105 & 0.130 \\
\hline EPara Intensity & 2.00 & .18 & 2.15 & .17 & 1.86 & .15 & 0.720 & 0.490 \\
\hline E Para IRIDI score & 7.46 & .79 & 8.30 & .70 & 6.59 & .66 & 1.379 & 0.259 \\
\hline Epithe st spinosum & 3.75 & .14 & 3.44 & .26 & 3.77 & .11 & 0.920 & 0.403 \\
\hline ESS Intensity & 2.04 & .19 & 2.26 & .21 & 2.14 & .15 & 0.350 & 0.706 \\
\hline ESS IRIDI score & 7.83 & .78 & 8.81 & .88 & 8.18 & .67 & 0.406 & 0.668 \\
\hline Total IRIDI Score & 22.96 & 2.22 & 25.41 & 2.05 & 21.64 & 1.82 & 0.881 & 0.419 \\
\hline CT stain & 1.25 & .32 & 2.00 & .32 & 1.41 & .32 & 1.614 & 0.206 \\
\hline CT intensity & .67 & .18 & 1.30 & .21 & 1.23 & .25 & 2.656 & 0.077 \\
\hline CT IRIDI score & 1.92 & .69 & 4.07 & .84 & 3.23 & .93 & 1.811 & 0.171 \\
\hline
\end{tabular}

Significant greater proportion of hyperplastic epithelium is seen in mild inflammation (34.21) and reduces as the severity of inflammation increases. The HSP 70 expression in stratum spinosum is higher in normal epithelium (range 21.21 to 78.79) (figure 2) compared to hyperplastic epithelium (range 44.7 to 5.26) (Table 4).

Figure 2a \& 2b Moderate positivity seen in the superficial part of epithelium HSP 70 expression is greater in stratum spinosum than basal and parabasal layers. Basal \& parabasal layers do not show any staining.

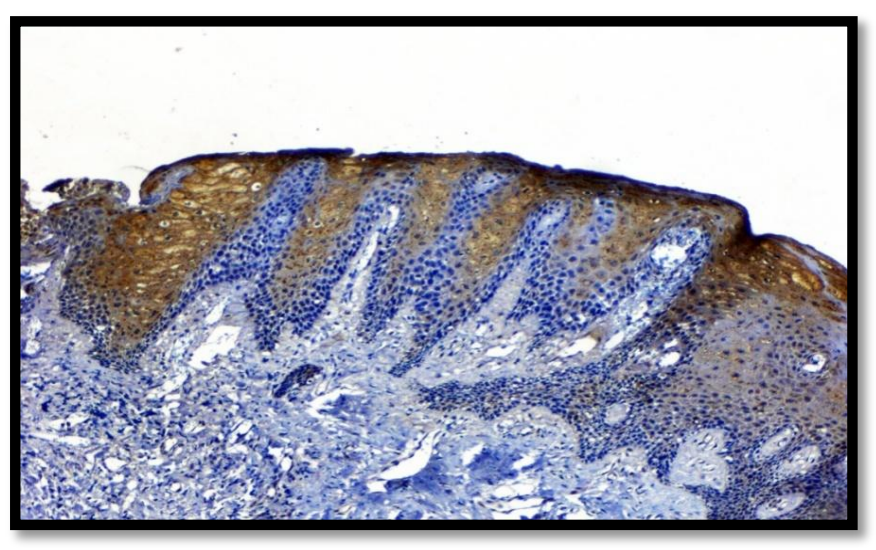

Figure 2 a) IHC 10x

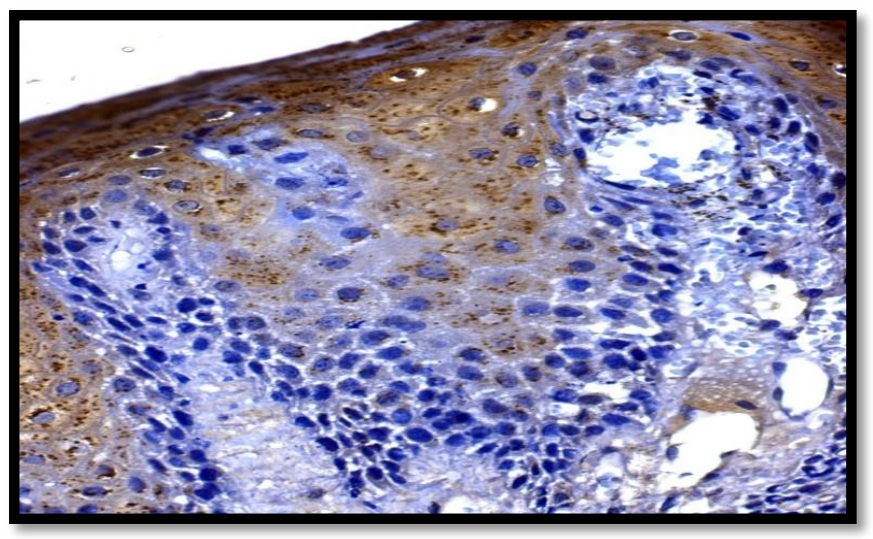

Figure 2 b) IHC 20x 
Table 4: Comparison of equality of proportions among the two groups of epithelium (mann whitney u test)

\begin{tabular}{|c|c|c|c|c|c|c|c|}
\hline & & \multicolumn{4}{|c|}{ Epithelium } & \multirow{2}{*}{\multicolumn{2}{|c|}{ Mann-Whitney Test }} \\
\hline & & \multicolumn{2}{|c|}{ Hyperplastic } & \multicolumn{2}{|c|}{ Normal } & & \\
\hline & & $\mathrm{n}$ & $\%$ & $\mathrm{n}$ & $\%$ & Mann Whitney U Value & Sig. \\
\hline \multirow[t]{2}{*}{ Gender } & Male & 21 & 56.76 & 22 & 68.75 & 521.000 & 0.309 \\
\hline & Female & 16 & 43.24 & 10 & 31.25 & & \\
\hline \multirow[t]{4}{*}{ Inflammation } & Minimum & 6 & 15.79 & 22 & 66.67 & 227.500 & 0.000 \\
\hline & Mild & 13 & 34.21 & 9 & 27.27 & & \\
\hline & Moderate & 11 & 28.95 & 2 & 6.06 & & \\
\hline & Dense & 8 & 21.05 & 0 & .00 & & \\
\hline \multirow[t]{2}{*}{ Ebasal HSP70 expression } & Low & 16 & 42.11 & 8 & 24.24 & 515.000 & 0.115 \\
\hline & $\mathrm{High}$ & 22 & 57.89 & 25 & 75.76 & & \\
\hline \multirow[t]{2}{*}{ E Para HSP70 expression } & Low & 15 & 39.47 & 10 & 30.30 & 569.500 & 0.423 \\
\hline & $\mathrm{High}$ & 23 & 60.53 & 23 & 69.70 & & \\
\hline \multirow[t]{2}{*}{ ESS HSP70 expression } & Low & 17 & 44.74 & 7 & 21.21 & 479.500 & 0.038 \\
\hline & $\mathrm{High}$ & 21 & 55.26 & 26 & 78.79 & & \\
\hline \multirow[t]{2}{*}{ Total HSP70 Expression } & Low & 2 & 5.26 & 1 & 3.03 & 613.000 & 0.643 \\
\hline & $\mathrm{High}$ & 36 & 94.74 & 32 & 96.97 & & \\
\hline \multirow[t]{2}{*}{ CT HSP70 expression } & Low & 18 & 47.37 & 10 & 30.30 & 520.000 & 0.145 \\
\hline & $\mathrm{High}$ & 20 & 52.63 & 23 & 69.70 & & \\
\hline
\end{tabular}

A significant proportion of inflammation in periodontitis increases statistically with severity of inflammation (moderate=26.9, dense-19.23). There is no significant change in HSP 70 expression based on diagnosis of periodontal disease (Table 5) (Kruskal wallis test)

Table 5: Comparison of equality of proportions among more than two groups of periodontal disease (kruskal wallis test)

\begin{tabular}{|c|c|c|c|c|c|c|c|c|c|}
\hline & & \multicolumn{6}{|c|}{ Diagnosis } & \multirow{2}{*}{\multicolumn{2}{|c|}{ Kruskal Wallis Test }} \\
\hline & & \multicolumn{2}{|c|}{ Gingivitis } & \multicolumn{2}{|c|}{ Periodontitis } & \multicolumn{2}{|c|}{ Healthy } & & \\
\hline & & $\mathrm{n}$ & $\%$ & $n$ & $\%$ & $\mathrm{n}$ & $\%$ & Chi-Square & Sig. \\
\hline \multirow[t]{2}{*}{ Gender } & Male & 13 & 56.52 & 15 & 55.56 & 16 & 76.19 & 2.527 & 0.283 \\
\hline & Female & 10 & 43.48 & 12 & 44.44 & 5 & 23.81 & & \\
\hline \multirow[t]{2}{*}{ Epithelium } & Hyperplastic & 12 & 52.17 & 18 & 69.23 & 8 & 36.36 & 5.126 & 0.077 \\
\hline & Normal & 11 & 47.83 & 8 & 30.77 & 14 & 63.64 & & \\
\hline \multirow[t]{4}{*}{ Inflammation } & Minimum & 8 & 34.78 & 7 & 26.92 & 13 & 59.09 & 7.246 & 0.027 \\
\hline & Mild & 9 & 39.13 & 7 & 26.92 & 6 & 27.27 & & \\
\hline & Moderate & 4 & 17.39 & 7 & 26.92 & 2 & 9.09 & & \\
\hline & Dense & 2 & 8.70 & 5 & 19.23 & 1 & 4.55 & & \\
\hline \multirow[t]{2}{*}{ EbasalHSP70 expression } & Low & 9 & 37.50 & 8 & 29.63 & 7 & 31.82 & 0.368 & 0.832 \\
\hline & $\mathrm{High}$ & 15 & 62.50 & 19 & 70.37 & 15 & 68.18 & & \\
\hline \multirow[t]{2}{*}{ EPara HSP70 expression } & Low & 9 & 37.50 & 8 & 29.63 & 8 & 36.36 & 0.407 & 0.816 \\
\hline & $\mathrm{High}$ & 15 & 62.50 & 19 & 70.37 & 14 & 63.64 & & \\
\hline \multirow[t]{2}{*}{ ESS HSP70 expression } & Low & 9 & 37.50 & 8 & 29.63 & 7 & 31.82 & 0.368 & 0.832 \\
\hline & $\mathrm{High}$ & 15 & 62.50 & 19 & 70.37 & 15 & 68.18 & & \\
\hline \multirow[t]{2}{*}{ Total HSP70 Expression } & Low & 1 & 4.17 & 1 & 3.70 & 1 & 4.55 & 0.022 & 0.989 \\
\hline & $\mathrm{High}$ & 23 & 95.83 & 26 & 96.30 & 21 & 95.45 & & \\
\hline \multirow[t]{2}{*}{ CT HSP70 expression } & Low & 12 & 50.00 & 8 & 29.63 & 8 & 36.36 & 2.251 & 0.324 \\
\hline & $\mathrm{High}$ & 12 & 50.00 & 19 & 70.37 & 14 & 63.64 & & \\
\hline
\end{tabular}

\section{Discussion}

Periodontitis is a chronic inflammatory disease that affects the tooth supporting tissue-the periodontium. It is the most frequent cause of tooth loss in the adult population. The prevalence of the disease is high, with the moderate form affecting $50 \%$ and the progressive form $5-15 \%$ of the adult population ${ }^{17}$. The prevalence of cardiovascular diseases in patients with periodontitis is 25-50\% higher than in healthy individuals.

Heat shock proteins have important functions in the cell such as folding, assembly, and translocation of polypeptides across membranes and play a main role in protein repair after cell damage. The human and bacterial cognates of heat shock proteins are similar, sharing more than $50 \%$ sequence homology at the amino acid level ${ }^{3}$. Heat shock protein production by several periodontopathic micro-organisms has been extensively documented. The presence of these stress proteins has been demonstrated in tissue samples from periodontitis lesions $^{18,7}$.

Yamazaki et al $(\mathbf{2 0 0 2})^{19}$ examined the proliferative response of peripheral blood mononuclear cells (PBMC), as well as the cytokine profile and T-cell clonality, for periodontitis patients and controls following stimulation with recombinant human hsp60 and Porphyromonas gingivalis GroEL. They demonstrated that Hsp60- specific $T$ cells accumulated in the gingival lesions of periodontitis patients but not in gingivitis patients and 
that the $T$ cell clones with an identical specificity to those in peripheral blood existed in periodontitis lesions.

Choi et al (2004) ${ }^{20}$ showed that Porphyromonas gingivalis Hsp reactive $T$ cell immune response might be involved in immunopathogenesis of periodontal disease. They suggested that $T$ cells in the circulating peripheral blood may home to periodontal lesions where Porphyromonas gingivalis have infiltrated potentially leading to $T$ cell response cross reactive to mammalian HSP of gingival fibroblasts. Of all heat shock proteins, the Hsp70 family constitutes the most conserved and best studied class. Earlier studies by Amina Gamal el Din et al $(\mathbf{2 0 1 0})^{16}$ evaluated the differential immunehistochemical expression of HSP 70 in psoriatic skin. Antibodies to HSP70 were analyzed immunehistochemically. Immunoreactivity intensity distribution index (IRIDI) scores including the proportion of immunoreactive cells and their staining intensity were calculated in the basal, suprabasal, superficial as well as the whole epidermal layers of patients and controls. HSP70 was not immunohistochemically detected in the dermis of normal skin. Intense HSP70 immunostaining was found in psoriatic lesions, predominantly in basal and suprabasal epidermal cell layers.

Asea et al (2000) ${ }^{9}$ have hypothesized that HSP 70 upregulated the expression of pro-inflammatory cytokines tumor necrosis factor (TNF)-alpha, interleukin (IL)-1beta and IL-6 in human monocytes. Due to their high conservation among various microbial pathogens and their ability to induce very strong immune responses, HSP 70s are thought to play a role as candidate antigens in periodontal disease.

In a study by Sergio Sanchez-Rodriguez et al (2011) ${ }^{21}$ looked for the expression of Hsp70, Hsp90 and P53 in the tissue of patients with chronic periodontal disease and gingivitis. There was an increase of Hsp70 and 90, and a slight increase in p53 levels. By PCR Hsp70 expression was increased in initial and progressive periodontitis and in a low level in advanced.

Our study aimed at comparing the HSP 70 expression within layers of epithelium and connective tissue and to correlate intensity of HSP 70 expression with severity of periodontal disease.

This study was of its first kind where detailed estimation of HSP 70 expression was seen in layers of epithelium and connective tissue.

Our results suggest that there is a greater intensity and staining in all the epithelium layers compared to connective tissue although not statistically significant. A statistically significant HSP70 expression in basal layer for mild inflammation IRIDI $(\mu=8.95)$ and intensity in stratum spinosum for mild $(\mu=8.73)$ and minimum inflammation $(\mu=9.29)$. The stratum spinosum has a significant HSP70 intensity and IRIDI score for mild and minimum inflammation group. The HSP70 expression in stratum spinosum is higher in normal epithelium compared to hyperplastic epithelium.

A statistically insignificant expression and intensity in different groups of periodontal disease. The total IRIDI score of HSP 70 expression in gingivitis group $(\mu=22.96)$ was greater than health group $(\mu=21.64)$ respectively and also comparatively greater than both health and gingivitis group in periodontitis $(\mu=25.41)$ even though it is not statistically significant due to smaller sample size.

This denotes the possible correlation exists in disease progression in periodontal disease. Even though intervention of immune response during the molecular mimicry between the bacterial and human HSP 70 is not feasible at this stage. A hand of heat shock proteins in the pathophysiology of periodontal disease helps us to intervene in the immune responses, by future studies to search for immunotherapeutic approach at suppressing the inflammatory response which is useful for therapeutic approaches of periodontal disease.

\section{Conclusion}

We elucidated that there was significant HSP expression in stratum basale and spinosum for mild inflammation that did not increase with severity of inflammation. The overall expression of HSP is insignificantly elevated in periodontitis compared to health \& gingivitis which shows the role of it in disease initiation and progression.

\section{References:}

1. Newman MG, Carranza FA, Takei H, Klokkevold PR. Carranzas clinical Periodontology. 10th ed. Elsevier health sciences; 2006.

2. Lindquist $S$, Craig EA. The heat-shock proteins. Annu Rev Genet, 22: 631-677, 1988.

3. Ellis JR, van Eden W, Young D. Stress proteins as molecular chaperones. Stress Proteins in Medicine 1996:1-26.

4. Latchman, D.S. (1991) Heat shock proteins and human disease. J. Royal Coll. Physic. London 25, 295-299.

5. Jindal, S. (1996) Heat shock proteins: Applications in health and disease. Trends Biotechnol. 14, 1720.

6. Feige, U., Morimoto, R.I., Yahara, I. and Polla, B. (eds., 1996) Stress Inducible Cellular Responses, EXS vol. 77.

7. Ando $\mathrm{T}$, Kato $\mathrm{T}$, Ishihara $\mathrm{K}$, Ogiuchi $\mathrm{H}$, Okuda $\mathrm{K}$ Heat shock proteins in the human periodontal disease 
process Oral Microbiol Immunol 1995 ; 39 :321327.

8. Seymour GJ, Gemmell E, Reinhardt RA, Eastcott J, Taubman MA. Immunopathogenesis of chronic inflammatory periodontal disease: cellular and molecular mechanisms. J Periodont Res, 28: 478486, 1993.

9. Asea A, Kraeft SK, Kurt-Jones EA, HSP70 stimulates cytokine production through a CD14dependant pathway, demonstrating its dual role as a chaperone and cytokine.NAT MED 2000 Apr;6(4):435-42.

10. Pockley AG, Shepard J, Corton JM. Detection of heat shock protein 70 (HSP 70) and anti Hsp 70 antibodies in the serum of normal individuals. Immunol investing 1998 27, 367-377.

11. Fabian TK, Fejerdy P, Csermely P. Chemical biology of saliva in health and disease. Begley T. Wiley Encyclopedia of chemical biology. Hoboken John Wiley \& Sons in press.

12. Jin Y Yip HK Supragingival calculus formation and control Crit Rev Oral Biol Med 2002 13, 426-441.

13. G. Wick, "Atherosclerosis-an autoimmune disease due to an immune reaction against heat-shock protein 60," Herz, vol. 25, no. 2, pp. 87-90, 2000.

14. Chaiyarit P, Kafrawy $A H$ and Miles DA (1999). Oral lichen planus: an immunohistochemical study of heat shock proteins (HSPs) and cytokeratins (CKs) and a unifying hypothesis of pathogenesis. J Oral Pathol Med; 28: 210-214.

15. Nutan Tyagi, Devi Charan Shetty, Aadithya B URS Altered expression of HSP70 in oral lichen planus
Journal of Oral and Maxillofacial Pathology Vol. 16 Issue 2 May - Aug 2012.

16. Amina Gamal el Din, Hanan $M$ Saleh, Immunohistochemical Expression of Heat Shock Protein 70 in Psoriasis Vulgaris. New York Science Journal. 2010;3(4):112-116]. (ISSN: 1554-0200).

17. R. C. Page, "Milestones in periodontal research and the remaining critical issues," Journal of Periodontal Research, vol. 34, no. 7, pp. 331-339, 1999.

18. Lundqvist C, Baranov V, Teglund S, Hammarstrom $\mathrm{S}$, Hammarstrom ML Cytokine profile and ultrastructure of intraepithelial gamma delta T cells in chronically inflamed gingiva suggest a cytotoxic effector function J Immunol 1994; 153: 2302-2312.

19. Yamazaki $K$, Ohsawa $Y$, Tabeta $K$, Ito $H$, Ueki $K$, Oda $T$, Yoshie $H$, Seymour GJ. Accumulation of human heat shock protein 60-reactive $T$ cells in the gingival tissues of periodontitis patients. Infect immuno 2002 May;70(5):2492-501.

20. J.I. Choi, S.-W. Chung H.-S. Kang Epitope Mapping of Porphyromonas gingivalis Heat-shock Protein and Human Heat-shock Protein in Human Atherosclerosis. Journal of dental research 2004 Dec;83(12):936-40.

21. Sergio Sanchez-Rodriguez, Lucio LópezMartínez, Increased expression of HSP70, HSP90 and P53 in tissue of patients with periodontal and gingivitis deceases. The Journal of Immunology, 2011, 186,59.6. 